Association for Information Systems

AIS Electronic Library (AISeL)

Wirtschaftsinformatik 2021 Proceedings

Track 10: Design, management and impact of

Al-based systems

\title{
User-specific Determinants of Conversational Agent Usage: A Review and Potential for Future Research
}

Lara Riefle

Karlsruhe Institute of Technology (KIT), Karlsruhe, Germany

Carina Benz

Karlsruhe Institute of Technology (KIT), Karlsruhe, Germany

Follow this and additional works at: https://aisel.aisnet.org/wi2021

Riefle, Lara and Benz, Carina, "User-specific Determinants of Conversational Agent Usage: A Review and Potential for Future Research" (2021). Wirtschaftsinformatik 2021 Proceedings. 1.

https://aisel.aisnet.org/wi2021/QDesign/Track10/1

This material is brought to you by the Wirtschaftsinformatik at AIS Electronic Library (AISeL). It has been accepted for inclusion in Wirtschaftsinformatik 2021 Proceedings by an authorized administrator of AIS Electronic Library (AISeL). For more information, please contact elibrary@aisnet.org. 


\title{
User-specific Determinants of Conversational Agent Usage: A Review and Potential for Future Research
}

\author{
Lara Riefle $^{1}$ and Carina Benz ${ }^{1}$ \\ ${ }^{1}$ Karlsruhe Institute of Technology, Karlsruhe, Germany \\ \{lara.riefle,carina.benz $@ @$ kit.edu
}

\begin{abstract}
Conversational agents (CAs) have become integral parts of providers' service offerings, yet their potential is not fully exploited as users' acceptance and usage of CAs are often limited. Whereas previous research is rather technology-oriented, our study takes a user-centric perspective on the phenomenon. We conduct a systematic literature review to summarize the determinants of individuals' acceptance, adoption, and usage of CAs that have been examined in extant research, followed by an interview study to identify potential for further research. In particular, five concepts are proposed for further research: personality, risk aversion, cognitive style, self-efficacy, and desire for control. Empirical studies are encouraged to assess the impact of these userspecific concepts on individuals' decision to use CAs to eventually inform the design of CAs that facilitate users' acceptance, adoption, and use. This paper intends to contribute to the body of knowledge about the determinants of CA usage.
\end{abstract}

Keywords: Conversational agent use, User behavior, Individual differences, User dispositions, Literature review

\section{Introduction}

Conversational agents (e.g., customer support chatbots) have become integral parts of providers' service offerings, yet their acceptance and usage are often limited. Providers (e.g., firms), for example, offer conversational agents (CAs) to people in customer service to answer individuals' questions about a firm's offerings [1,2]. They promise time savings and efficiency gains. Similarly, Apple offers the intelligent agent Siri on its smartphones to assist users with a variety of topics such as meeting scheduling, weather updates, or navigation [2,3]. Nevertheless, practice reports that after an initial hype, CA usage significantly drops. Users do not continue to use them regularly and often only resort to their assistance for menial tasks such as searching the FAQ or setting a cooking timer [4]. Some people even ignore them completely. Thus, the enormous potential of CAs is not fully exploited and providers withdraw them from their service offerings again [5]. This problem of poor user acceptance and inconsistent usage is also investigated in the literature, with researchers exploring the underlying causes in their search for remedies [3]. Information Systems (IS) literature provides two models that are regularly applied in studies on user behavior: the Technology 
Acceptance Model (TAM) [6] and the Unified Theory of Acceptance and Use of Technology (UTAUT) [7]. For decades, users' acceptance and usage of technology has been studied based on these two models and recently CAs have become a central research topic. Taking a predominantly technology-focused perspective, researchers have examined how CAs are perceived [e.g., 8], how different design features affect users [e.g., 9], or how the usage experience can be improved [e.g., 10]. Still, existing literature cannot fully explain why people do not accept and use chatbots or intelligent agents. A more user-centric perspective on individuals' acceptance, adoption, and usage of CAs is necessary to understand what drives people to use them. Thus, we intend to answer the following research questions:

What is the current state of research on the determinants of individuals' acceptance, adoption, and usage of CAs? Which concepts should be covered by future research?

To address these questions, we apply a mixed-method approach comprising a systematic literature review (SLR) to provide an overview of the body of knowledge, and an additional interview study to identify overlooked concepts. Thereby we arrive at a research agenda on facilitating individual acceptance and usage of CAs. The literature-based framework compiles the major determinants and corresponding concepts that influence individuals in their decision to use CAs. Five additional concepts emphasizing user-specific factors are identified by means of the interviews. The findings indicate that we need to better understand the users themselves - their individual differences and dispositions - to ultimately be able to advance the acceptance and use of CAs. Overall, this study aims to contribute to the body of knowledge about the determinants of the usage of CAs in particular and AI-based systems in general. The proposed conceptual framework might serve as a basis for both IS researchers and practitioners to successfully design and implement CAs.

The remainder of this paper is structured as follows: First, we provide a brief summary of the background on CAs and research on usage, adoption, and acceptance theories. Second, the research methodology is outlined. Next, we present an integrated framework that aggregates existing research findings on the usage, adoption, and acceptance of CAs. Finally, we derive directions for further research and discuss theoretical and practical implications.

\section{Theoretical Background}

\subsection{Conversational Agents}

Conversational agents are defined as software-based systems that interact with the user in natural language $[1,11]$. These conversational user interfaces can refer to text-based CAs, such as chatbots, or speech-based CAs, e.g., intelligent agents such as Apple's Siri. Typically CAs are applied in messaging applications, on websites, or, in the case of intelligent agents, embedded in devices, to assist users in various use cases $[2,11]$. On e-commerce sites, for example, CAs offer users maximum availability. They can provide fast answers to their questions, or represent a convenient way for users to complete tasks such as ordering food [12]. Smalltalk-oriented CAs can even fulfill users' social needs [12]. Thus, CAs may offer a number of advantages in users' 
everyday lives. All this is enabled by artificial intelligence (AI), more precisely by machine learning and natural language processing [13].

The use of AI makes CAs and other AI-based systems special [14]. Two crucial aspects distinguish them from other information systems: their degree of interactivity and intelligence [14]. These characteristics allow AI-based systems to interact with users in a human-like way and take over tasks from them. Interactions can even take forms that are so similar to interpersonal communication that emotional bonds between the user and CAs might develop [15]. Researchers have shown that users often perceive AI-based systems as social and autonomous actors [16]. Hence, the anthropomorphism questions basic assumptions of information systems as mere machines or tools [17]. Users' perceptions, attitudes, and beliefs about AI-based systems, particularly CAs, may be fundamentally affected $[13,17]$.

\subsection{Acceptance, Adoption, and Usage Theories in IS}

Research on acceptance, adoption, and usage of information systems is of central interest in the IS research stream on user behavior. Although the three terms are often used synonymously, they shall be distinguished in this paper: Acceptance is described as a state or an individuals' attitude that marks the start of the adoption process; which may eventually end with the usage (one-time or continued) [18]. Different models have been introduced over the years to explain users' usage intentions and behavior on the individual level. The most commonly applied theories in IS are the Technology Acceptance Model (TAM) [6] and the Unified Theory of Acceptance and Use of Technology (UTAUT) [7]. Central concepts in these theories are the perceived usefulness and the perceived ease of use, i.e., the user's perceptions of a systems' performance and effort of using it $[7,19,20]$. Incorporated in TAM and UTAUT are the socio-psychological Theory of Planned Behavior (TPB) [21] and the Theory of Reasoned Action (TRA) [22]. These add social and cognitive concepts to the models as further influencing factors of users' behavior [20]. Over the years, TAM and UTAUT have been extended to increase their explanatory power [20]. Still, the underlying assumption of these models is that users' intention to use is a good predictor of actual usage of the system under investigation [20].

Another less frequently used theory to explain user behavior is the IS Continuance Model [23]. In contrast to TAM and UTAUT, the IS Continuance Model is concerned with the post-adoption stage of information systems. The model focuses on users' continued IS use linking satisfaction and perceived usefulness (from TAM) to the individual's intention to continue using a system [23]. Thus, the model draws on consumer behavior research by building on expectation-confirmation theory and including cognitive beliefs and affect to model users' behavior.

The strengths of the theories and models above to explain IS usage lies in a few wellstudied determinants: users' perceptions, attitudes, expected outcomes, and their (social) environment. As has been suggested by Schuetz and Venkatesh [17], current advancements of AI-based systems such as CAs make them considerably different from previous information systems. This raises the question in how far user behavior with 
regard to CAs can be explained drawing on established models and where further research may be needed.

\section{$3 \quad$ Methodology}

In order to (1) identify determinants of acceptance, adoption, and usage of chatbots in extant research and (2) derive directions for future research, a mixed-method approach is applied. We conduct a systematic literature review (SLR) according to the guidelines suggested by vom Brocke et al. [24] and Webster and Watson [25] and synthesize the identified determinants of CA acceptance and usage in an integrated framework. This framework is then complemented by a subsequent interview study to identify potential for future research. We conduct 81 structured interviews and analyze them using qualitative content analysis according to Mayring [26]. To facilitate reproducibility and ensure transparency, we adhere to established research methods. The methodological steps taken are outlined below.

Systematic Literature Review (Step 1). To provide an overview of the body of knowledge on why people accept, adopt, and use CAs, we conduct an SLR. The scope of the SLR can be defined by its process, sources, coverage, and techniques [24]: In a sequential search process, four databases (i.e., sources) covering IS research and literature from related fields such as HCI are searched. Representative coverage of literature on the acceptance and usage of CAs is pursued by applying a keyword search, backward search, and forward search (i.e., techniques).

In detail, our search strategy involves searching in databases that cover IS research (i.e., AISeL), the related field of HCI research (i.e., ACM Digital Library), as well as interdisciplinary databases (i.e., Scopus, Web of Science) to account for the broad application of CAs across domains. The search string ([“"(conversational OR intelligent OR virtual OR cognitive OR smart OR digital OR AI) AND (assistant* OR agent* OR system* OR application*)"] OR chatbot*) AND ["use" OR "usage" OR "adoption" OR "acceptance"] includes related terms for CAs and yields a total of 953 hits (30.06.2020). 122 relevant articles (without duplicates) remain after screening title and abstract and applying the inclusion criteria as outlined in Table 1. 69 respectively six additional articles are added by backward and forward search. To also cover more recent research, next to journal articles also conference publications are included during the selection process. In addition, articles only marginally concerned with CA usage are excluded to ensure only relevant articles that promote further insights are considered. Table 1 provides a more detailed overview of the distribution of articles.

A total of 197 articles are considered in the literature analysis and synthesis process. Since our main interest lies in the concepts that have been investigated to understand individual user behavior, we first sort out 155 articles with a strong technology-focus. As suggested by Webster and Watson [25], a concept-matrix to structure the subsequent analysis is created. We scrutinize the full text of 42 articles and extract the concepts that determine individuals' acceptance, adoption, and usage of CAs. Each concept is assigned once per article, yet one article can cover several concepts. This process allows us to build a framework of concepts that have been studied in extant research. 
Table 1. Results of the literature search process

\begin{tabular}{|c|c|c|c|}
\hline Databases & Hits & Relevant & Inclusion criteria \\
\hline AISeL & 38 & 17 & \multirow{5}{*}{$\begin{array}{l}\text { - Peer-reviewed publications } \\
\text { in English } \\
\text { - Empirical data is collected } \\
\text { - Focus on acceptance, } \\
\text { adoption, or usage of CAs }\end{array}$} \\
\hline $\mathrm{ACM}$ & 108 & 22 & \\
\hline Scopus & 712 & 101 & \\
\hline Web of Science & 95 & 25 & \\
\hline Total & 953 & 122 w/o duplicates & \\
\hline+69 Backward & & +6 Forward search & $=197$ articles \\
\hline
\end{tabular}

Interview Study (Step 2). The framework derived from the SLR is complemented with further concepts by an interview study. While the SLR provides an overview of existing knowledge on CA acceptance, adoption, and use, the interview study reveals promising concepts for future research. We interview 81 purposefully sampled interviewees (university students at the age of $21-28,57 \%$ male) about their usage of CAs and the underlying drivers. The structured interviews cover their general attitude towards using $\mathrm{CAs}$, their actual use of CAs, the conditions under which they use CAs, and the influencing factors on their decision to use CAs. $44 \%$ of interviewees are regular CA users, $32 \%$ occasional users, and $24 \%$ non-users, which allows us to investigate a broad spectrum of users.

Qualitative content analysis is performed in an iterative process following the approach by Mayring [26]. Central statements in the interview data are paraphrased, reduced, and aggregated using the software MAXQDA. The initial deductive category assignment aims at verifying the previously identified concepts determining individuals' acceptance, adoption, and usage. Aiming at identifying promising concepts for future research, we next concentrate on those statements that could not be matched with a concept of the literature-based framework but still are relevant to the research questions. During the subsequent inductive category assignment, the statements are coded according to the two-cycle recommendations of Saldaña [27]. In the first cycle, descriptive coding is applied to summarize the main topic of each statement, which is then followed by pattern coding in the second cycle to aggregate the descriptive firstcycle codes to a higher level of abstraction for further in-depth analysis. In this final analysis step, five additional concepts are identified in the interviews that represent concepts in IS and psychology that promise further insights into user behavior with regard to CAs. These five concepts further enrich the framework derived in the SLR and facilitate a more comprehensive view of the determinants of individuals' acceptance, adoption, and usage of CAs. 


\section{$4 \quad$ Results}

\subsection{Determinants and Concepts Investigated in Extant Literature}

Existing literature on CA acceptance, adoption, and usage can be classified along three research foci (see Figure 1): (1) Almost half (48\%) of the 197 analyzed articles evaluate a specific CA artifact, (2) about one third (31\%) compare the effect of different technological CA features on users, and (3) only $21 \%$ put the user in the center of attention investigating the determinants of their acceptance and usage of CAs.

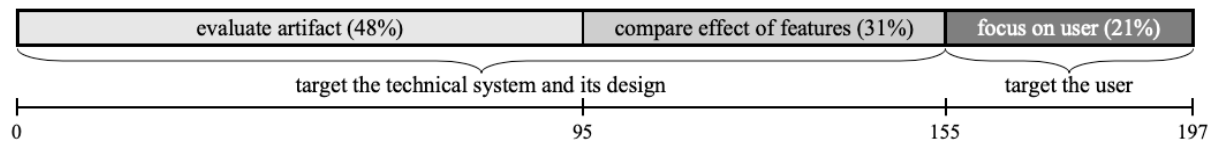

Figure 1. Focus of existing literature on $\mathrm{CA}$ acceptance, adoption, and usage

A total of $79 \%$ of analyzed articles, i.e., with research foci (1) and (2), target the technical system and its design. They seek to advance the knowledge of how design features influence the user to finally improve the CAs as such. The evaluation of a specific artifact with users is the main purpose of 95 articles. Typically, CA artifacts are developed, e.g., using a Design Science Research approach [28], and then evaluated by asking users for their acceptance of the artifact and their usage intention. Most often $(83 \%)$, the articles do not draw on specific concepts from theory for the evaluation [29]. However, in case they do, TAM or UTAUT concepts such as perceived usefulness or ease of use are applied [30]. Overall, very specific CAs built for limited use cases are investigated. Thus, these articles can only marginally contribute to answering the stated research question posed regarding the determinants of individuals' acceptance, adoption, and usage of CAs.

The main purpose of another 60 articles is to compare the effect of different technological CA features on users. For example, they investigate how language style influences information disclosure [e.g., 31] or how CA appearance affects continued human-agent interaction [e.g., 32]. Central topics of interest are social cues, next to error handling mechanisms [e.g., 33], or response characteristics [e.g., 2]. Often, the papers develop design recommendations to improve users' experience during CA usage. The contributions made enhance our understanding of the actual usage phase. However, further literature must be considered to also understand users' decision to accept and use CAs in the first place.

Lastly, 42 articles take a closer look at the users themselves focusing, for example, on their perceptions, attitudes, and experiences. These articles contribute to exploring the usage phase, but also provide further insights into the preceding acceptance and adoption of CA, which is why we examine them in detail. To extract the determinants of individual user behavior the articles are analyzed in a concept-centric approach. The resulting framework is summarized in Table 2 (numbers indicate the number of articles that investigated the concept). 
Table 2. The main determinants of an individual's CA usage investigated in extant research

\begin{tabular}{|c|c|c|c|c|c|c|c|}
\hline Concept & Definition & |â. & 幽 & 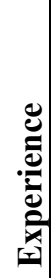 & : & 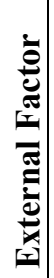 & 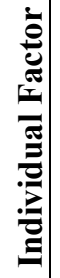 \\
\hline $\begin{array}{l}\text { Perceived } \\
\text { Usefulness }\end{array}$ & $\begin{array}{l}\text { "the degree to which an individual believes } \\
\text { that using a particular system would enhance } \\
\text { his or her performance" }[6, \text { p. } 112]\end{array}$ & 13 & & & & & \\
\hline $\begin{array}{l}\text { Performance } \\
\text { Expectancy }\end{array}$ & $\begin{array}{l}\text { "the degree to which an individual believes } \\
\text { that using the system will help him or her } \\
\text { attain gains in performance" [7, p. 447] }\end{array}$ & 7 & & & & & \\
\hline $\begin{array}{l}\text { Perceived Ease } \\
\text { of Use }\end{array}$ & $\begin{array}{l}\text { "the degree to which an individual believes } \\
\text { that using a particular system would be free } \\
\text { of physical or mental effort" [6, p. } 112]\end{array}$ & 15 & & & & & \\
\hline $\begin{array}{l}\text { Effort } \\
\text { Expectancy }\end{array}$ & $\begin{array}{l}\text { "the degree of ease associated with the use of } \\
\text { the system" }[7, \text { p. } 450]\end{array}$ & 8 & & & & & \\
\hline Perceived Risk & $\begin{array}{l}\text { "extent of customers' perception of } \\
\text { uncertainty" }[34, \text { p. 4297] }\end{array}$ & 9 & & & & & \\
\hline $\begin{array}{l}\text { Attitude toward } \\
\text { CA Usage }\end{array}$ & $\begin{array}{l}\text { "the user's positive or negative feelings } \\
\text { (evaluative affect) about performing a } \\
\text { specific behavior" }[35, \text { p. } 247]\end{array}$ & & 10 & & & & \\
\hline Trust & $\begin{array}{l}\text { "the extent to which one is willing to ascribe } \\
\text { good intentions to and have confidence in } \\
\text { the words and actions of other people" [ } 36 \text {, } \\
\text { p. 39] }\end{array}$ & & 11 & & & & \\
\hline $\begin{array}{l}\text { Prior } \\
\text { Experience with } \\
\text { the System }\end{array}$ & $\begin{array}{l}\text { The background and knowledge the } \\
\text { individual has with using a particular system } \\
{[7]}\end{array}$ & & & 6 & & & \\
\hline $\begin{array}{l}\text { Prior } \\
\text { Experience with } \\
\text { the Task }\end{array}$ & $\begin{array}{l}\text { The background and knowledge the } \\
\text { individual has with completing a particular } \\
\text { task [7] }\end{array}$ & & & 5 & & & \\
\hline $\begin{array}{l}\text { Hedonic } \\
\text { Motivation }\end{array}$ & $\begin{array}{l}\text { "pleasure derived from using a technology" } \\
{[37, \text { p. 161] }}\end{array}$ & & & & 6 & & \\
\hline $\begin{array}{l}\text { Utilitarian } \\
\text { Motivation }\end{array}$ & $\begin{array}{l}\text { Behavior driven from functional, goal- } \\
\text { oriented motives [38] }\end{array}$ & & & & 1 & & \\
\hline $\begin{array}{l}\text { Social } \\
\text { Motivation }\end{array}$ & $\begin{array}{l}\text { Behavior driven from social and relational } \\
\text { motives [39] }\end{array}$ & & & & 1 & & \\
\hline
\end{tabular}




\begin{tabular}{|c|c|c|c|c|c|c|c|}
\hline Concept & Definition & |ã & | & & | & 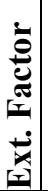 & \\
\hline Social Influence & $\begin{array}{l}\text { "the extent to which consumers perceive that } \\
\text { important others (e.g., family and friends) } \\
\text { believe they should use a particular } \\
\text { technology" }[37, \text { p. } 159]\end{array}$ & & & & & 5 & \\
\hline Innovativeness & $\begin{array}{l}\text { "the degree to which an individual or other } \\
\text { unit of adoption is relatively earlier in } \\
\text { adopting new ideas than the other members } \\
\text { of his social system" }[40, \text { p. } 22]\end{array}$ & & & & & & 3 \\
\hline Demographics & Factors such as age, gender, ethnicity & & & & & & 5 \\
\hline
\end{tabular}

The emphasis on concepts from TAM and UTAUT can clearly be recognized. Perceived usefulness and perceived ease of use from TAM, which are closely related to performance expectancy and effort expectancy from UTAUT, are among the most researched concepts [e.g., 41, 42]. The perception of risk (e.g., user's perceived security and data privacy risk) is less commonly investigated [e.g., 43, 44]. The relevance of these established concepts is further underlined in the interview statements: Interviewee \#66, for example, states "I use chatbots in order to save time and get my tasks done more easily". This indicates perceived usefulness or performance expectancy, respectively. Perceived ease of use and effort expectancy are pointed out in statements such as "[the CA is] able to help me quickly and in an uncomplicated manner" (I36) and "chatbots are easy to use" (I6). Statements by I32, I67, I72, I80, and others further support these determinants; i.e., users need to perceive a CA as performance-enhancing and easy to use in order to actually use them. Likewise, the perceived risk associated with CAs is reflected in statements such as "[I am] not quite sure that conversational agents provide a proper data security" (I42) or "I find many conversational agents too intrusive" (I3). Together, these perceptions of users are often studied and seem to be an important determinant of CA acceptance, adoption, and usage.

A user's attitude toward CA usage is also well-researched in existing literature [e.g., $42,45]$. TAM also includes the concept of attitude toward usage, which originates from TRA and TPB. This affective response - positive or negative - can also be seen in users' statements: "I love using conversational agents" (I78) or "I am still skeptical of the skills of these machines" (I79). In addition, trust toward the CA is investigated by, for example, Kasilingam [43], Laumer et al. [44], or Prakash and Das [46]. Some interviewees expressed a lack of trust as I35's statements documents "I do not really trust the chatbot that it can find the best fitting solution for me. So, I would need to check the result anyway". The interviews show another interesting aspect. Attitudes are formed or reinforced, though not necessarily, based on prior experience (e.g., I79: "This experience verified my skeptical attitude against conversational agents"). In terms of prior experience, a distinction can be made between prior experience with the system 
[e.g., 47], i.e., CAs, and prior experience with the task [e.g., 44]. I3's statement "I feel that in $90 \%$ of the cases I am not well advised by chatbots and contact the hotline or the support directly" suggests that the concept of prior system experience influences the decision to use a CA.

Hedonic, utilitarian, and social motivation are further concepts that are considered by researchers investigating the acceptance, adoption, and usage of CAs [e.g., 12, 41, 46]. While extensions of UTAUT include hedonic motivation as a concept, motivations are originally rooted in social psychology research. Uses and Gratifications Theory [48] assumes that individuals have a clear intent when using a system, i.e., their behavior is goal-driven. In the interviews, these different goals or motivations become apparent: hedonic - e.g., "sometimes I talk to it just for fun" (I47), utilitarian - e.g., "I use them because of higher flexibility" (I67), and social - e.g., "when I am bored, [the CA] is just like a friend to accompany you" (I61). Next to these intrinsic motivations, external factors such as social influence can affect an individual in his or her usage decision [34, $41,44,46]$. For example, I20 states that he has been influenced by his friends to test a certain CA.

As a last determinant, individual factors of the user are investigated in extant research. Demographic factors such as age, gender, and ethnicity, and the individual's innovativeness are explored as concepts by Kasilingam [43], Nadarzynski et al. [49], or Melián-González et al. [41]. Individual factors, especially innovativeness, are confirmed by statements such as "I was curious to test it" (I20) or "I am trying to familiarize myself with the novel technological tool" (I66).

The outlined determinants and concepts (see Table 2) are the main determinants of users' acceptance, adoption, and usage of CAs that have been regarded in extant literature. The results show that research to date especially contributed to expanding our knowledge about users' perceptions and attitudes towards CAs and the influence of prior experience and friends and family's opinion. Only initial attempts have been made to gain a deeper understanding of individual user-specific factors determining CA acceptance and usage. Yet, our interviews with potential and actual CA users suggest that there are further relevant concepts that might enable us to facilitate CA acceptance and usage.

\subsection{Potential for Future Research Based on Concepts Emerging from the Interviews}

We have set out to investigate what research has done to understand individuals' acceptance, adoption, and usage of CAs (RQ1). The SLR shows that the majority of existing research is concerned with the technology itself by evaluating a specific artifact with users or comparing the effect of different design features on users. Only little research focuses on the users themselves. These articles on user behavior have examined a multitude of concepts: users' perceptions of the system; their attitudes towards using CAs; users' prior experience; their hedonic, utilitarian, and social motivations; social influence; and individual factors such as innovativeness or demographics. In addition, this study aimed at identifying potential for future research (RQ2). To this end, we conducted interviews and derived five concepts (see Table 3) 
that offer potential for further research. Our results suggest that user-specific concepts, i.e., individual factors, need to be studied to understand why people accept, adopt, and use CAs.

Table 3. Preliminary research agenda on user-specific factors influencing individuals' acceptance, adoption, and usage of CAs

\begin{tabular}{|c|c|c|}
\hline Concept & Definition & Exemplary Research Questions \\
\hline & $\begin{array}{l}\text { The individually different } \\
\text { combination of cognitions, } \\
\text { emotions and behavior patterns } \\
\text { that evolve from biological and } \\
\text { environmental influences [50] }\end{array}$ & \multirow{5}{*}{ 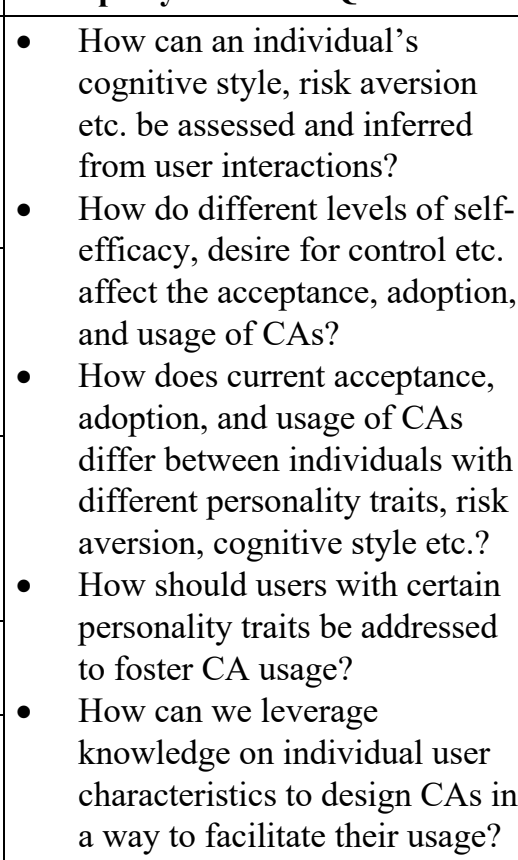 } \\
\hline $\begin{array}{l}\text { Risk } \\
\text { Aversio }\end{array}$ & $\begin{array}{l}\text { "An individual's degree of } \\
\text { negative attitude toward risk } \\
\text { arising from outcome } \\
\text { uncertainty" [51, p. 533] }\end{array}$ & \\
\hline $\begin{array}{l}\text { Cognitive } \\
\text { Style }\end{array}$ & $\begin{array}{l}\text { The set of cognitive processes } \\
\text { that influence how an } \\
\text { individual perceives and forms } \\
\text { judgments [52] }\end{array}$ & \\
\hline $\begin{array}{l}\text { Self- } \\
\text { Efficacy }\end{array}$ & $\begin{array}{l}\text { An individual's belief in his/her } \\
\text { own skills and abilities [53] }\end{array}$ & \\
\hline $\begin{array}{l}\text { Desire for } \\
\text { Control }\end{array}$ & $\begin{array}{l}\text { The intensity of an individual's } \\
\text { innate psychological need for } \\
\text { control [54] }\end{array}$ & \\
\hline
\end{tabular}

Personality. Interviewee \#66 made the statement "I like to use cutting-edge technologies as I'm a computer geek" (I66), expressing that he seeks new experiences and is generally open to try out novel technologies. I59 stated "I don't like the feeling of talking to a machine [...] I personally would like to hear or feel how the other side reacts to my concern", which indicates that she values personal contact and empathetic conversation in case of a problem. Despite the differences, both statements can be attributed to the concept of personality, which is generally described by five traits: openness, agreeableness, neuroticism, conscientiousness, and extraversion known as the Big Five personality traits [55]. Each of these traits is differently pronounced in each individual, which leads to distinct cognitions, emotions, and behavior. In the case of I66, the trait openness ("geek", open to try out) seems to be strong, whereas the wish for establishing relationships and interpersonal interactions in the latter statement by I59 is typical for individuals with a high degree of agreeableness.

Risk aversion. I42 notes that it is "not quite clear in which cases [CAs] can help you and in which they are not that useful", which is why he avoids using them to prevent wasting his time. Similarly, due to uncertainties regarding the "proper data security" of 
CAs, I7 tries "to either avoid them or at least [does] not provide too much details" about herself. These statements show that both interviewees limit their CA usage due to uncertainties about CAs' usefulness and data security, which points to the concept of risk aversion. In this context, risk aversion is not only understood in the narrower economic sense, i.e., in terms of calculable financial losses but rather encompasses the general level of risk (arising from outcome uncertainty) that an individual is willing to incur [51]. Different degrees of individual risk aversion lead to different risk-reducing behavior [56]: While I42's risk aversion is so pronounced that he avoids CAs completely, I7's risk aversion is expressed in cautious usage, and I8's risk aversion is so weak that she does "not mind to interact with [CAs]" (I7).

Cognitive Style. Statements such as "for me it is sometimes hard to explain my case by written language" (I63) relate to the fact that individuals are known to prefer different ways of communication and information input (e.g., written, verbal, visual, haptic). Furthermore, I2 states that she "did not consciously make use of [the chatbot]", she just used it when it was presented to her. This shows that her way of processing information is intuitive rather than analytical. Analytical information processing implies decomposing information into its components; as is the case for I16 and I34 who separate the information of becoming aware of the chatbot popping-up, from the information about other alternatives on the website to achieve their goal (e.g., finding product details) and consequently only use the $\mathrm{CA}$ after weighing up the alternatives. Both the preference for a particular information representation and the way of processing the presented information are aggregated in the theoretical concept of cognitive style [52]. Research investigates a multitude of cognitive styles, i.e., sets of cognitive processes that influence how an individual perceives and forms judgment. Yet, especially the verbal-oriented cognitive style - as indicated in I63's preference for spoken language - and the field-independent cognitive style - observable in I16 and I34's analytic information processing - stood out in the interviews as influencing CA usage [52].

Self-Efficacy. I35's statement "As I assess myself, I am an independent person, preferring doing things by myself" reveals that she thinks she has the necessary skills and abilities to complete the task on her own without CA assistance. Then again, I7 states to resort to the help of CAs to solve problems as this option is "faster than [she] would find an appropriate solution on [her] own" (I7). This varying belief of individuals in their own abilities and skills is reflected in the concept of self-efficacy [53, 57]. In our interviews, we observed that depending on the level of self-efficacy, individuals were more or less inclined to use CAs. Individuals (e.g., I35) with a high level of selfefficacy refrained from CA assistance, whereas individuals such as I7 with a lower selfefficacy assessed her abilities in such a way that it seemed better for her to ask the CA for support.

Desire for Control. I62 mentions to enjoy using the chatbot of a retailer as a "shopping assistant to help [her] choose the right style" as it guides her through the shopping process by "prompt[ing] the user to answer some basic questions" (I62). It is in I62's interest that the CA takes the lead during the conversation and decides on how to proceed. Other interviewees, on the contrary, are annoyed by the fact that often the CA controls the interaction, for example, when the customer service chatbot "decides 
whether to forward the inquiry to a human service employee" (I8). This obviously different innate need for control of the two interviewees is described by the concept of desire for control [54]. While some individuals want to have more control over the CA's actions (e.g., I8), others are willing to cede control to the CA and let it decide how to proceed in the conversation (e.g., I62).

Overall, current research on CA acceptance, adoption, and usage has a strong tendency towards technology and design-oriented issues. Thereby, a user's individual characteristics are often only marginally considered which does not correspond to their significance for acceptance, adoption, and usage. It must be considered how users' dispositions influence their perceptions and attitudes. For instance, an individual's unmet desire for control may result in a lack of trust in the system; or a high level of individual risk aversion could increase the amount of perceived risk of CAs, finally leading to the decision to not use the system. Hence, this study aims to reemphasize the value of individual factors for CA acceptance, adoption, and usage. We encourage future research to (re)focus on the user of CAs - their characteristics and dispositions - as determinants for system usage. Only with a sound understanding of the users and their individual differences, CA usage can be reliably predicted and enhanced. For example, only when CA designers are aware of differences in personality and cognitive styles, and their implications for adoption and usage, they can adapt CA design towards individual preferences. Once designers know that the intended system users are characterized by a high degree of self-efficacy influencing their behavior, they can ensure that they design the system in such a way that it does not undermine their competence.

To arrive there, empirical research will be an important means to further explore the user-specific concepts identified in this study, to measure their influence, and examine possible interdependencies. Research questions guiding these endeavors are provided in Table 3: To build a basis for a more nuanced perspective on CA acceptance, adoption, and usage, it is necessary to identify different user profiles in terms of personality traits, cognitive style, risk aversion, self-efficacy, and desire for control. Building on these insights future research should then test and quantify the influence of the identified concepts on individuals' acceptance, adoption, and usage of CAs. Only then will it be possible to design systems that are tailored to the users and ultimately target their enhanced acceptance, adoption, and usage of CAs.

\section{$5 \quad$ Limitations}

This study aimed to provide a basis for understanding users' acceptance, adoption, and usage of CAs. This aim has been pursued through a rigorous SLR and a subsequent interview study. We nevertheless acknowledge a few limitations of our study that provide avenues for future research. Although the scope of the SLR is not fully comprehensive, a database-oriented search including journal articles and conference publications was chosen. This way, more recent research could be considered, which is particularly important as the research field of human interaction with CAs is still young 
and emerging. Regarding the interview study, a drawback is that only a certain group of people, i.e., university students between $21-28$, have been interviewed. However, by restricting the interview sample to digital natives familiar with the concept of CAs it was ensured that only relevant data was collected to complement the study. Finally, the overall research focused on the context of CAs as only one type of AI-based systems, which is why it may be an interesting research avenue for future studies to extend the results to other types of AI-based systems (e.g., wearables).

\section{Conclusion}

In this paper, we investigated the main determinants of individuals' acceptance, adoption, and usage of CAs. Our goal was to better understand what could cause current CA usage to fall short of expectations and, therefore, not fully exploit the potential of these AI-based systems. We took a literature-based approach enriched by empirical insights from interviews. The systematic literature review (SLR) containing 197 articles shows that the strength of existing literature lies in explaining users' perceptions and attitudes. Building on 81 interviews, we derived five additional concepts comprising users' individual factors, i.e., their dispositions and individual differences. On that foundation potential for future research was outlined. We propose that, to enable successful CAs and their continued use, research and practice need to better understand the individual user - their cognitive style, risk aversion, desire for control, etc.. It is important to build a deeper knowledge of users' personality, individual differences, and dispositions. Only then can we facilitate users' acceptance, adoption, and continued usage of CAs and other AI-based systems.

The contribution of this paper is twofold: from a theoretical point of view, we provide a systematic review of existing research on users' acceptance, adoption, and usage of CAs. The integrated framework of concepts may serve as an orientation for researchers in the field of user behavior. In addition, we present five concepts (see Table 3) pertaining to user-specific individual factors that emerged from our study as offering potential for future research. The importance of users' individual characteristics is highlighted, and a research agenda is proposed. From a practical point of view, a better understanding of the user and awareness of individual differences and dispositions will help to figure out how to facilitate the successful acceptance, adoption, and usage of CAs. Hence, a potential starting point toward the individualized design of CAs is presented. All in all, the emerging user-specific factors may serve as a valuable foundation to investigate individual acceptance, adoption, and usage of CAs in more detail.

\section{$7 \quad$ Acknowledgements}

The authors acknowledge the financial support by the Federal Ministry for Economic Affairs and Energy of Germany in the project Service-Meister (project number 01MK20008). 


\section{References}

1. McTear, M., Callejas, Z., Griol, D.: The Conversational Interface: Talking to Smart Devices. Springer (2016).

2. Gnewuch, U., Morana, S., Adam, M., Maedche, A.: Faster is Not Always Better: Understanding the Effect of Dynamic Response Delays in Human-Chatbot Interaction. In: Twenty-Seventh European Conference on Information Systems (ECIS). pp. 1-17. Porthsmouth (2018).

3. Grudin, J., Jacques, R.: Chatbots, humbots, and the quest for artificial general intelligence. In: Conference on Human Factors in Computing Systems (CHI). pp. 1-11. Glasgow (2019).

4. Liao, Q.V., Hussain, M.M.U., Chandar, P., Davis, M., Khazaen, Y., Crasso, M.P., Wang, D., Muller, M., Shami, N.S., Geyer, W.: All Work and No Play? Conversations with a Question-and-Answer Chatbot in the Wild. In: Conference on Human Factors in Computing Systems (CHI). pp. 1-13. Montreal (2018).

5. Ben Mimoun, M.S., Poncin, I., Garnier, M.: Case study-Embodied virtual agents: An analysis on reasons for failure. J. Retail. Consum. Serv. 19, 605-612 (2012).

6. Davis, F.D.: Perceived usefulness, perceived ease of use, and user acceptance of information technology. MIS Q. Manag. Inf. Syst. 13, 319-339 (1989).

7. Venkatesh, V., Morris, M.G., Davis, G.B., Davis, F.D.: User Acceptance of Information Technology: Toward a Unified View. MIS Quaterly. 27, 425-478 (2003).

8. Lee, S., Lee, N., Sah, Y.J.: Perceiving a Mind in a Chatbot: Effect of Mind Perception and Social Cues on Co-presence, Closeness, and Intention to Use. Int. J. Hum. Comput. Interact. 36, 930-940 (2020).

9. Go, E., Sundar, S.S.: Humanizing chatbots: The effects of visual, identity and conversational cues on humanness perceptions. Comput. Human Behav. 97, 304-316 (2019).

10. Biduski, D., Bellei, E.A., Rodriguez, J.P.M., Zaina, L.A.M., De Marchi, A.C.B.: Assessing long-term user experience on a mobile health application through an in-app embedded conversation-based questionnaire. Comput. Human Behav. 104, 106169 (2020).

11. Følstad, A., Brandtzaeg, P.B.: Chatbots and the New World of HCI. Interactions. 24, 38 42 (2017).

12. Brandtzaeg, P.B., Følstad, A.: Why people use chatbots. In: 4th International Conference of Internet Science (INSCI). pp. 377-392. Thessaloniki (2017).

13. Maedche, A., Legner, C., Benlian, A., Berger, B., Gimpel, H., Hess, T., Hinz, O., Morana, S., Söllner, M.: AI-Based Digital Assistants. Opportunities, Threats, and Research Perspectives. Bus. Inf. Syst. Eng. 61, 535-544 (2019).

14. Maedche, A., Morana, S., Schacht, S., Werth, D., Krumeich, J.: Advanced user assistance systems. Bus. Inf. Syst. Eng. 58, 367-370 (2016).

15. Pfeuffer, N., Benlian, A., Gimpel, H., Hinz, O.: Anthropomorphic Information Systems. Bus. Inf. Syst. Eng. 61, 523-533 (2019).

16. Pakkala, D., Spohrer, J.: Digital Service: Technological Agency in Service Systems. In: 52nd Hawaii International Conference on System Sciences (HICSS). pp. 1886-1895. , Grand Wailea, Maui (2019).

17. Schuetz, S., Venkatesh, V.: The rise of human machines: How cognitive computing 
systems challenge assumptions of user-system interaction. J. Assoc. Inf. Syst. 21, 1-42 (2020).

18. Karahanna, E., Straub, D.W., Chervany, N.L.: Information technology adoption across time: A cross-sectional comparison of pre-adoption and post-adoption beliefs. MIS Q. Manag. Inf. Syst. 23, 183-213 (1999).

19. Davis, F.D.., Bagozzi, R.P.., Warshaw, P.R..: User Acceptance of Computer Technology: A Comparison of Two Theoretical Models. Manage. Sci. 35, 982-1003 (1989).

20. Constantiou, I.D., Lehrer, C., Hess, T.: Changing information retrieval behaviours: An empirical investigation of users' cognitive processes in the choice of location-based services. Eur. J. Inf. Syst. 23, 513-528 (2014).

21. Ajzen, I.: The Theory of Planned Behavior. Organ. Behav. Hum. Decis. Process. 50, 179211 (1991).

22. Fishbein, M., Ajzen, I.: Belief, attitude, intention, and behavior: An introduction to theory and research. Addison-Wesley, Reading, MA and Don Mills, Ontario (1975).

23. Bhattacherjee, A.: Understanding Information Systems Continuance: An ExpectationConfirmation Model. MIS Q. 25, 351-370 (2001).

24. vom Brocke, J., Simons, A., Riemer, K., Niehaves, B., Plattfaut, R., Cleven, A.: Standing on the shoulders of giants: Challenges and recommendations of literature search in information systems research. Commun. Assoc. Inf. Syst. 37, 205-224 (2015).

25. Webster, J., Watson, R.T.: Analyzing the past to prepare for the future : Writing a literature review. MIS Q. 26, xiii-xxiii (2002).

26. Mayring, P.: Qualitative Content Analysis: Theoretical Background and Procedures. In: Bikner-Ahsbahs, A., Knipping, C., and Presmeg, N. (eds.) Approaches to qualitative research in mathematics education: examples of methodology and methods. pp. 365-380 (2015).

27. Saldaña, J.: The Coding Manual for Qualitative Researchers. SAGE, London (2009).

28. Hevner, A.R., March, S.T., Park, J., Ram, S.: Design Science in Information Systems Research. MIS Q. 28, 75-105 (2004).

29. Rodriguez, J., Piccoli, G., Bartosiak, M.: Nudging the Classroom: Designing a SocioTechnical Artifact to Reduce Academic Procrastination. In: 52nd Hawaii International Conference on System Sciences (HICSS). pp. 4405-4414. Grand Wailea, Maui (2019).

30. Hobert, S.: Say Hello to 'Coding Tutor'! Design and Evaluation of a Chatbot-based Learning System Supporting Students to Learn to Program. In: Fortieth International Conference on Information Systems (ICIS). pp. 1-17. Munich (2019).

31. Gnewuch, U., Meng, Y., Maedche, A.: The Effect of Perceived Similarity in Dominance on Customer Self-Disclosure to Chatbots in Conversational Commerce. In: Twenty-Eighth European Conference on Information Systems (ECIS). pp. 1-16. Marrakesh (2020).

32. Liao, Y., He, J.: Racial Mirroring Effects on Human-Agent Interaction in Psychotherapeutic Conversations. In: 25th International Conference on Intelligent User Interfaces. pp. 430-442. Cagliari (2020).

33. Sheehan, B., Jin, H.S., Gottlieb, U.: Customer service chatbots: Anthropomorphism and adoption. J. Bus. Res. 115, 14-24 (2020).

34. Patil, K., Kulkarni, M.S.: Artificial intelligence in financial services: Customer chatbot advisor adoption. Int. J. Innov. Technol. Explor. Eng. 9, 4296-4303 (2019).

35. Malhotra, Y., Galletta, D.F., Kirsch, L.J.: How endogenous motivations influence user 
intentions: Beyond the dichotomy of extrinsic and intrinsic user motivations. J. Manag. Inf. Syst. 25, 267-300 (2008).

36. Cook, J., Wall, T.: New work attitude measures of trust, organizational commitment and personal need non-fulfilment. J. Occup. Organ. Psychol. 53, 39-52 (1980).

37. Venkatesh, V., Thong, J.Y.L., Xu, X.: Consumer Acceptance and Use of Information Technology: Extending the Unified Theory of Acceptance and Use of Technology. MIS Q. 36, 157-178 (2012).

38. Childers, T.L., Carr, C.L., Peck, J., Carson, S.: Hedonic and utilitarian motivations for online retail shopping behavior. J. Retail. 77, 511-535 (2001).

39. Brandtzaeg, P.B., Følstad, A.: Why people use chatbots. In: 4th International Conference of Internet Science (INSCI). pp. 377-392. Thessaloniki (2017).

40. Rogers, E.M.: Diffusion of Innovations. Free Press, New York, London, Toronto, Sydney, Singapore (2003).

41. Melián-González, S., Gutiérrez-Taño, D., Bulchand-Gidumal, J.: Predicting the intentions to use chatbots for travel and tourism. Curr. Issues Tour. 0, 1-19 (2019).

42. Richad, R., Vivensius, V., Sfenrianto, S., Kaburuan, E.R.: Analysis of factors influencing millennial's technology acceptance of chatbot in the banking industry in Indonesia. Int. J. Manag. 10, 107-118 (2019).

43. Kasilingam, D.L.: Understanding the attitude and intention to use smartphone chatbots for shopping. Technol. Soc. 62, 101280 (2020).

44. Laumer, S., Maier, C., Gubler, T.F.: Chatbot acceptance in healthcare: Explaining user adoption of conversational agents for disease diagnosis. In: Twenty-Seventh European Conference on Information Systems (ECIS). pp. 1-18. Stockholm-Uppsala (2019).

45. Araújo, T., Casais, B.: Customer Acceptance of Shopping-Assistant Chatbots. In: Rocha, Á., Reis, J.L., Peter, M.K., and Bogdanović, Z. (eds.) Smart Innovation, Systems and Technologies. pp. 278-287 (2020).

46. Prakash, A.V., Das, S.: Intelligent Conversational Agents in Mental Healthcare Services: A Thematic Analysis of User Perceptions. Pacific Asia J. Assoc. Inf. Syst. 12, 1-34 (2020).

47. Nadarzynski, T., Miles, O., Cowie, A., Ridge, D.: Acceptability of artificial intelligence (AI)-led chatbot services in healthcare: A mixed-methods study. Digit. Heal. 5, 1-12 (2019).

48. Rubin, A.M.: Uses and Gratifications. In: The SAGE handbook of media processes and effects. pp. 147-159 (2009).

49. Nadarzynski, T., Bayley, J., Llewellyn, C., Kidsley, S., Graham, C.A.: Acceptability of artificial intelligence (AI)-enabled chatbots, video consultations and live webchats as online platforms for sexual health advice. BMJ Sex. Reprod. Heal. 1-18 (2020).

50. Corr, P.J., Matthews, G.: The Cambridge Handbook of Personality Psychology. Cambridge University Press, Cambridge, New York, Melbourne, Madrid, Cape Town, Singapore, São Paulo, Delhi, Dubai, Tokyo (2009).

51. Mandrik, C.A., Bao, Y.: Exploring the Concept and Measurement of General Risk Aversion. Adv. Consum. Res. 32, 531-539 (2005).

52. Benbasat, I., Taylor, R.N.: The Impact of Cognitive Styles on Information System Design. MIS Q. 2, 43 (1978).

53. Wood, R., Bandura, A.: Social Cognitive Theory of Organizational Management. Acad. Manag. Rev. 14, 361-384 (1989). 
54. Bakke, S., Henry, R.: Unraveling the Mystery of New Technology Use: An Investigation into the Interplay of Desire for Control, Computer Self-efficacy, and Personal Innovativeness. AIS Trans. Human-Computer Interact. 7, 270-293 (2015).

55. McCrae, R.R., Costa, P.T.: A Five-Factor Theory of Personality. In: Handbook of Personality: Theory and Research. pp. 139-153. Guilford, New York (1999).

56. Oreg, S., Bayazit, M.: Prone to Bias: Development of a Bias Taxonomy From an Individual Differences Perspective. Rev. Gen. Psychol. 13, 175-193 (2009).

57. Chen, G., Gully, S.M., Eden, D.: Validation of a New General Self-Efficacy Scale. Organ. Res. Methods. 4, 62-83 (2001). 